http://www.sciforum.net/conference/wsf-4

\title{
Sustainable Agriculture and Climate Change: Producing Potatoes (Solanum tuberosum L.) and Bush Beans (Phaseolus vulgaris L.) for Improved Food Security and Resilience in a Canadian Subarctic First Nation Community
}

\author{
Christine D. Barbeau ${ }^{1, *}$, Maren Oelbermann ${ }^{1, \dagger}$, Jim D. Karagatzides ${ }^{2}$, and Leonard J.S. Tsuji \\ $1,3, \dagger$
}

1 Department of Environment and Resource Studies, University of Waterloo, Waterloo, ON, Canada N2L 3G1; E-Mail: cbarbeau@uwaterloo.ca

1 Department of Environment and Resource Studies, University of Waterloo, Waterloo, ON, Canada N2L 3G1; E-Mail: moelbermann@uwaterloo.ca

3 School of Environmental Studies, Georgia College, Barrie, ON, Canada, L4M 3X9; E-Mail:

Jim.Karagatzides@GeorgianCollege.ca

${ }^{1,3}$ Health Studies, and the Department of Physical and Environmental Sciences, University of Toronto Scarborough, Toronto, ON, Canada M1C 1A4 E-Mail: leonard.tsuji@utoronto.ca

$\dagger$ These authors contributed equally to this work.

* Author to whom correspondence should be addressed; E-Mail: cbarbeau@uwaterloo.ca; Tel.: 1-519-502-2502.

Received: 1 September 2014 / Accepted: 13 October 2014 / Published: 1 November 2014

\footnotetext{
Abstract: Aboriginal people in Canada's northern regions are vulnerable to climate variability in addition to experiencing disproportionately high rates of diet-related illnesses including obesity, diabetes, and heart disease. Food insecurity is a contributing factor along with a loss of traditional lifestyles. Current food systems within these regions rely heavily on imported foods that are expensive (when available), and unsustainable. A warming subarctic and arctic climate offers the opportunity for local agricultural production that can increase food security and promote a more sustainable food system. In this study the feasibility of sustainably growing potatoes (Solanum tuberosum L.) to enhance food security in remote subarctic communities is explored through a case study in Fort Albany First Nation in northern Ontario, Canada. Potato crops were grown over a two-year period and rotated into plots that had been planted with green bush beans (Phaseolus vulgaris L.) Results showed that
} 
potatoes and bush beans could be grown successfully in the subarctic with yields comparable to more traditional agricultural methods. In subarctic Canada, sustainable local food production helps to promote social capital, healthier lifestyles, and food security.

Keywords: Food Security; Aboriginal; Sustainable Food Production; Arctic; Subarctic

\section{Introduction}

\subsection{Canadian Aboriginal Health}

Aboriginal groups (Metis, Inuit and First Nations) face a shorter life expectancy from birth compared to non-Aboriginal Canadians [1]. This difference in life expectancy has been attributed to numerous environmental factors such as, overcrowding, poverty, environmental contamination, geospatial remoteness, and food insecurity [2-4]. Insufficient access to nutritional foods has resulted in disproportionately high rates of obesity in Aboriginal communities. Over the last 25 years, obesity rates in Aboriginal communities rose more than 50\% compared to the rest of Canada [5]. At present, obesity rates in Aboriginal children and adolescents are increasing which will ultimately lead to increased incidences of diet-related illnesses, such as, type 2 diabetes and cardiovascular disease [6-9].

Food insecurity in Aboriginal populations in Canada has been described as an urgent issue that must be addressed [10]. Indeed, results from the 2008 First Nations Regional Health Survey found that among Canadian Aboriginals over 50\% of households were considered to be food insecure. The high rate of food insecurity in Aboriginal Canadian communities has been attributed to multiple factors including environmental contamination, climate change, and the movement away from a traditional subsistence diet to a modern diet [7]. Further, there appears to be a strong relationship between food security and community location [7]. It was suggested that the more northerly and remote a community's location, the higher the incidence of food insecurity [13,7]. Prevalence rates have been reported as high as 70\% for remote Aboriginal communities (2014). For the purposes of this research, northern Aboriginal communities are defined as communities in arctic and subarctic regions north of the $51^{\circ}$ latitude.

\subsection{Current Food Systems in Northern Canadian Aboriginal Communities}

Historically, traditional diets included wild game, berries and plants that promoted physical and mental health [13]. However, with time, a decline in the amount of traditional food consumed in many Aboriginal communities occurred. The loss of hunting and fishing for traditional meats was attributed to numerous barriers including a rise in gasoline prices, unpredictable and dangerous environmental conditions, and lack of time [14]. Furthermore, a loss of Indigenous knowledge due to the Government of Canada's attempt to assimilate Aboriginal Canadians into "mainstream" Canadian society resulted in a loss of knowledge on hunting, gathering and traditional food preparation techniques [13]. Today, many northern diets contain little traditional food with wild meat, fish and berries replaced with modern import-based processed foods $[13,15]$.

A major barrier to eating nutritious market foods in many arctic and subarctic communities is the high cost of poor-quality food items, and when produce is available, it is often spoiled [7,15-17]. 
Due to geospatial constraints and climate, the majority of food available in northern Aboriginal communities is imported by air year-round, by sea during the ice-free summer months, and by winter ice-road after freeze-up. Not only does remoteness result in food prices, 2-4 times that in southern communities, it also perpetuates an unsustainable petroleum-based economy, contributing to greenhouse gas emissions.

Efforts were made by the Canadian Government through the Nutrition North program to improve the affordability and availability of fresh and nutritious foods in remote communities. These efforts were associated with mixed success. Critics noted that this program is tailored to what is considered a healthy lifestyle by "outsiders" and there is little control of produce quality $[10,18]$. Despite attempts from the Canadian Government to improve food security in northern communities, recent research in one remote First Nation community revealed that $100 \%$ of respondents interviewed worried about having enough food and if they could afford to eat balanced meals [19].

\subsection{Current Global Agricultural Practices}

The current northern-Canadian, import-based food system is unsustainable with the majority of imported food produced in southern regions through conventional high-input agricultural practices. Current intensive agriculture "has come to draw the inputs which it uses from more distant sources, both spatially and sectorally, to derive an increasing proportion of its energy supplies from nonrenewable sources, to depend upon a more narrow genetic base and to have an increasing impact on the environment. This is particularly reflected in its heavy reliance on chemical fertilizers and pesticides, its dependence upon subsidies and price support and its external costs such as threats to other species, environmental pollution, habitat destruction and risks to human health and welfare" [20:3]. Therefore, there is a need for sustainable, healthy and local-subsistence food systems to meet not only the nutritional needs of Aboriginal Canadians living in northern regions, but also, to promote social and ecological health. Historically, agriculture in northern Canada was severely limited by temperature; however, a warming climate gives us an opportunity to better understand the potential for more sustainable agricultural practices in the north [21].

\subsection{More Sustainable Agriculture in Canada's North}

Despite an agricultural industry that is worth billions, agriculture in Canada is limited by a short growing season and harsh temperatures [21]. Southern Canadian regions experience a growing season of approximately 200 days while northern arctic and subarctic regions can see growing periods as little as a few weeks [21]. Severe winter temperatures and early frost harm crops; harsh winds and blowing snow make it hard for northern communities to grow crops naturally for food and to generate economic income from local markets. However, the predicted rate of temperature increase for northern regions is nearly double that of the global average, with temperatures expected to increase $5-7^{\circ}$ [2224]. With warming temperatures, the growing season in arctic areas such as Yellowknife and Whitehorse will be similar to that of Edmonton today by the year 2050 [21]. Such agricultural opportunities can promote increased food security within rural, remote and isolated communities.

Fresh produce, grown more sustainably and locally can have positive health effects and decrease the reliance on costly imported foods. Promotion of local, more sustainable agriculture in Aboriginal communities in the Canadian arctic and subarctic has the potential to enhance food security 
in a sustainable way. Warming temperatures in the Canadian arctic and subarctic present an opportunity to investigate the potential for local, more sustainable food production in Aboriginal communities. The aim of this study was to examine the potential to more sustainably grow potatoes in a subarctic First Nations community with the goal of helping to enhance food security.

\section{Methods}

\subsection{Research Community}

The First Nations community of Fort Albany was chosen as the location for this pilot study. Fort Albany is located in the Canadian subarctic on the western James Bay coast, northern Ontario, Canada. Located along the south shore of the Albany River $\left(52^{\circ} 15^{\prime} \mathrm{N}, 81^{\circ} 35^{\prime} \mathrm{W}\right)$, Fort Albany is a remote fly-in community with a population of approximately 850 people. Within the community there is one grocery store and two small convenience stores where groceries can be purchased. However, availability of produce is highly variable and often-staple food items, such as, potatoes are unavailable for weeks. Traditional foods such as moose (Alces alces), caribou (Rangifer tarandus), waterfowl, and fish are an important part of many community members' diets; however, accessibility issues such as travel costs, unpredictable travel conditions, and changes in bird migration patterns have made the procurement and consumption of traditional foods a challenge [14].

The western James Bay region is characterized by short, cool summers (mean annual temperature of $-1.1{ }^{\circ} \mathrm{C}$ ) with large amounts of annual rain $(728 \mathrm{~mm})$ and annual growing degree-days (a measure of accumulated heat energy) of $830\left(>5{ }^{\circ} \mathrm{C}\right)$ [25]. Fort Albany, like many other communities in arctic and subarctic regions of the world, has already experienced climatic warming [26]. Climate change modeling for this region predicts a future increase in surface-air temperatures and summer rainfall events resulting in potentially favorable agricultural conditions [14, 22, 24-28].

Fort Albany has a history of unsustainable agricultural practices [13]. In 1930, Roman Catholic Missionaries cleared some areas close to the community, and planted and maintained large areas of potato, turnip (Brassica rapa) and hay [13]. Smaller gardens were planted with beet (Beta vulgaris), radish (Raphanus sativus), cabbage (Brassica oleracea var. capitata) lettuce (Lactuca sativa), strawberry (Fragaria ananassa), onion (Allium spp.), tomato (Solanum lycopersicon) and carrot (Daucus carota) [13]. This agricultural land was maintained using machinery and chemicals; crops were watered during dry periods from a nearby lake and cow manure was used as fertilizer. Greenhouses were also utilized. Community members were required to work in the fields to help plant, maintain and harvest the crops, thereby taking people away from spending time practicing traditional skills [13]. By the 1970s, Missionary support of conventional agriculture stopped, although some community members continued to plant small patches of potatoes, for several years. Research has shown that community members view gardens as "a means to acquire produce at a cheaper price, especially potatoes, which are favored but very expensive" [13:8].

\subsection{More Sustainable Potato Production}

The potato makes for an ideal crop as a starting point in helping to foster and promote more sustainable local-food production in northern Aboriginal communities. There are historical accounts dating back to 1858 of potatoes playing an important role in cultural traditions in some Canadian First Nation communities [29]. Further, the potato has become a staple of the modern diet in northern 
communities. Taking into account the cost to air transport potatoes due to weight, makes the purchase of potatoes in the north, expensive; thus, producing potatoes locally would make potatoes relatively inexpensive. Further, the potato is a cool climate crop that has a requirement of $1000-1100\left(>5^{\circ} \mathrm{C}\right)$ growing degree-days to reach optimum harvest [30]. In addition, the potato is extraordinarily adaptive, easy to cultivate, has a long storage life and is nutritious. It contains 110 calories per serving (a $150 \mathrm{~g}$ medium potato), a high amount of antioxidants and nearly half of the recommended daily intake of vitamin $\mathrm{C}$. With more potassium than a banana and $10 \%$ of the daily value of dietary fiber and iron, potatoes help support a nutritious diet [31]. For the purposes of the presented research, the Shepody Potato variety cultivar was selected, after a pilot study of a variety of potato types in 2011 . The Shepody is a white fleshed, russet potato that is well adapted to a short growing season. It is an ideal baking and cooking potato that requires $10-20 \%$ less nitrogen than other varieties [32].

In order to promote more sustainable potato production, Good Agricultural Practices (GAPs) from the Food and Agriculture Organization of the United Nations were used as a guideline in the implementation of this research [33]. By definition, GAPs are "principles and codes of practice that are applied to on-farm production and post-production processes and aim at ensuring safe and healthy food and non-food agricultural products while taking into account economical, social and environmental sustainability" [33:19]. Soil and water conservation are two leading GAP principles. Thus, our methods included minimal tillage, hand-weeding, and leaving crop residue in the field to conserve the natural resource base. Potatoes were grown in rotation to help prevent disease and pests. Potatoes were also planted the second year in areas that had been previously planted with legumes [33]. In this study, bush beans were picked as the legumes to be used in rotation with potatoes because they provide a nutritious crop throughout the growing season. The Provider Bush Bean cultivar was chosen because this variety is known for tolerating a cool soil temperature, a short growing season, with high yields, and a sweet taste.

\subsection{Site Description}

A two-year field study was conducted in the community of Fort Albany First Nation. Two sites were suggested by community members to plant potato crops. The sites were located within a few hundred meters of the community, far enough away to avoid any disturbances but close enough to the community for logistical reasons. Detailed soil and vegetation analyses were carried out by Spiegelaar et al. who noted that the sites had soil conditions amenable for agricultural use [34]. The treed site (Site B) was located within mature, parallel rows of willow (Salix spp.) growing on the banks of old drainage ditches. The open site (Site C) was located $189 \mathrm{~m}$ from the treed site, in an open field without any trees. Soil samples from all sites were collected to carry out toxicological analyses - a suite of persistent organic pollutants and a suite of toxic metals - since there is a history of environmental contamination in many First Nation reserves across Canada. Soil toxicological results showed that sites $\mathrm{B}$ and $\mathrm{C}$ had acceptable levels for agricultural use. The treed site had three plots of potato and three plots of bean measuring $10.0 \mathrm{~m} \times 3.3 \mathrm{~m}$, while the open site had three potato and three bean plots measuring $9.0 \mathrm{~m} \times 3.3 \mathrm{~m}$. The size of each plot was determined by the stands of willow and natural contours of the land. The locations of each plot within each site were randomly assigned for the first field season, and used again in the second field season. 


\subsection{Field Season 2012}

Commencing in late May 2012, each site was prepared for planting. In order to maintain appropriate water content, old drainage trenches were re-dug or new ones dug between each plot. The trenches were dug as deep as possible, to control soil moisture within the crops as recommended by Spiegelaar et al. [34]. All sites were mechanically tilled with two vertical and two horizontal passes to ensure a tilled depth of approximately $20 \mathrm{~cm}$. Any biomass on the soil surface was tilled into the soil to help enhance levels of soil organic matter, as recommended by Spiegelaar et al. [34].

\subsubsection{Planting}

Planting of potatoes and beans took place on June 7, 2012, Shepody seed potatoes were acquired from a commercial supplier located $404 \mathrm{~km}$ south of the community. They were stored in a cool, dark basement for one week prior to planting. The seed potatoes were examined prior to cutting for any signs of disease, and any potentially diseased tuber was discarded. Each seed was cut with a clean knife ensuring they had at least two eyes. Potatoes were planted by hand to a shovel depth of $\sim 30$ $\mathrm{cm}$ and soil was then mounded over each potato after being placed by shovel into the soil. Potatoes were planted in rows $81.8 \mathrm{~cm}$ apart, with $28.0 \mathrm{~cm}$ between plants. Bush bean seed was purchased from a commercial retailer. The bush beans were planted to depth of $3.8 \mathrm{~cm}$, in rows $50.0 \mathrm{~cm}$ apart, with $11.4 \mathrm{~cm}$ between each plant.

After plant emergence, hand-weeding around the plants began, and continued throughout the growing season. In early August 2012, hoes were used to mound soil onto the potatoes. Rainfall throughout the summer was adequate for the growing crops; that is, no supplemental water was required.

\subsubsection{Potato and Bean Harvest}

Beginning mid-August 2012, bush beans were ready to be harvested. Beans were picked from a sub-sample plot of $2.5 \mathrm{~m}$ x $5.0 \mathrm{~m}$ located in the middle of each plot. These samples were weighed and the weights of the pods were recorded. The yield (tonnes/hectare) of bush bean was calculated for each site. Those bush beans harvested from the sites were given to the community.

The potato plots were harvested on September 25, 2012. A sub-sample plot measuring $1.5 \mathrm{~m} \mathrm{x}$ $1.0 \mathrm{~m}$ was taken in the center of each potato plot. The number of potato plants and potatoes were noted within each sub-sample plot. The potatoes were exposed to the air to cure and placed in labeled mesh bags. The potatoes were weighed and the weight was recorded. These sub-sample potatoes from the treed and open sites were then given to community members. Once this sampling was completed for all sites there was a community harvest day.

\subsubsection{Community Potato Harvest}

Potatoes left in both sites were then harvested through a community harvest day that was advertised on social media. Community members came out and were shown how potatoes were grown and harvested. They were also taught proper storage methods for their harvest. Numerous families including children and Elders came out. Each family took home one or two $9 \mathrm{~kg}$ bags of potatoes. 


\subsection{Field Season 2013}

An unusually cold and wet spring delayed the start of planting by a few days compared to 2012 . Beginning June 7, 2013, crop residue from the previous year was worked into the soil using a small push tiller using one pass vertically and horizontally. Planting took place on June 9, 2013. Location of the potato plots was reversed from the previous field season to allow for the potatoes to be planted in the bean plots. Unlike the previous season, beans were over-seeded and then thinned upon emergence to ensure an optimal plant spacing of $11.4 \mathrm{~cm}$, since it was noted that the seed planted the previous season had sub-optimal germination

The first two weeks after planting were drier than the previous year and the plots required watering by hand. Water was obtained from surrounding irrigation trenches. The 2013 season saw more community engagement in the way of weeding, mounding of potatoes and general care. Following the 2012 methodology, beans were harvested beginning August 28, 2013.

The potato harvest took place on October 6, 2013, following the 2012 methods. Again a community potato harvest day took place on October 9, 2013. Again, families took home approximately $9 \mathrm{~kg}$ of potatoes each. To better understand what community members thought of the project and of the future of potato production in the community several community members were interviewed. These interviews followed a semi-structured style and were audio-recorded with permission by the interviewee. The interviews were then transcribed verbatim into electronic format. The transcriptions were analyzed following a template organizing approach $[35,36]$.

\subsection{Data Analysis of Mean Yield}

Differences in the mean values of potato and bush bean yields between sites and between years were examined using two-way analysis of variance (ANOVA). Results were considered to be significant when $\mathrm{p}<0.05$. Data analyses were carried out using the program SPSS version 22 (SPSS Inc., Chicago, Illinois, U.S.A.). Analysis of the variance of means revealed that the mean yields for the potatoes were not equal, however this has been shown to have little effect on the level of significance in ANOVA [37]. Analysis of the variance of means for the bush bean yields revealed that the mean yields showed equal variance and therefore, supported the homogeneity of variance assumption of ANOVA.

\section{Results}

\subsection{Potato Yields}

The treed site (Site B) produced the greatest yield of potatoes over both field seasons, and produced double the yield of the open site (Site C) in 2013 (Figure 1). There was no significant interaction between year and site $(\mathrm{p}=0.27)$ and there was no statistical significance between years in potato production $(\mathrm{p}=0.95)$. There was however, a significant $(\mathrm{p}=0.02)$ difference in the potato yields between the treed and open sites. In addition, in 2012, the mean weight of a potato for the treed site was $115.39 \mathrm{~g}$ and $89.68 \mathrm{~g}$ for the open site. The mean potato weight for the 2013 field season was $136.67 \mathrm{~g}$ for the treed site and $83.33 \mathrm{~g}$ for the open site. Not only did the treed site produce a larger yield than the open site, but also the potatoes were also larger. 


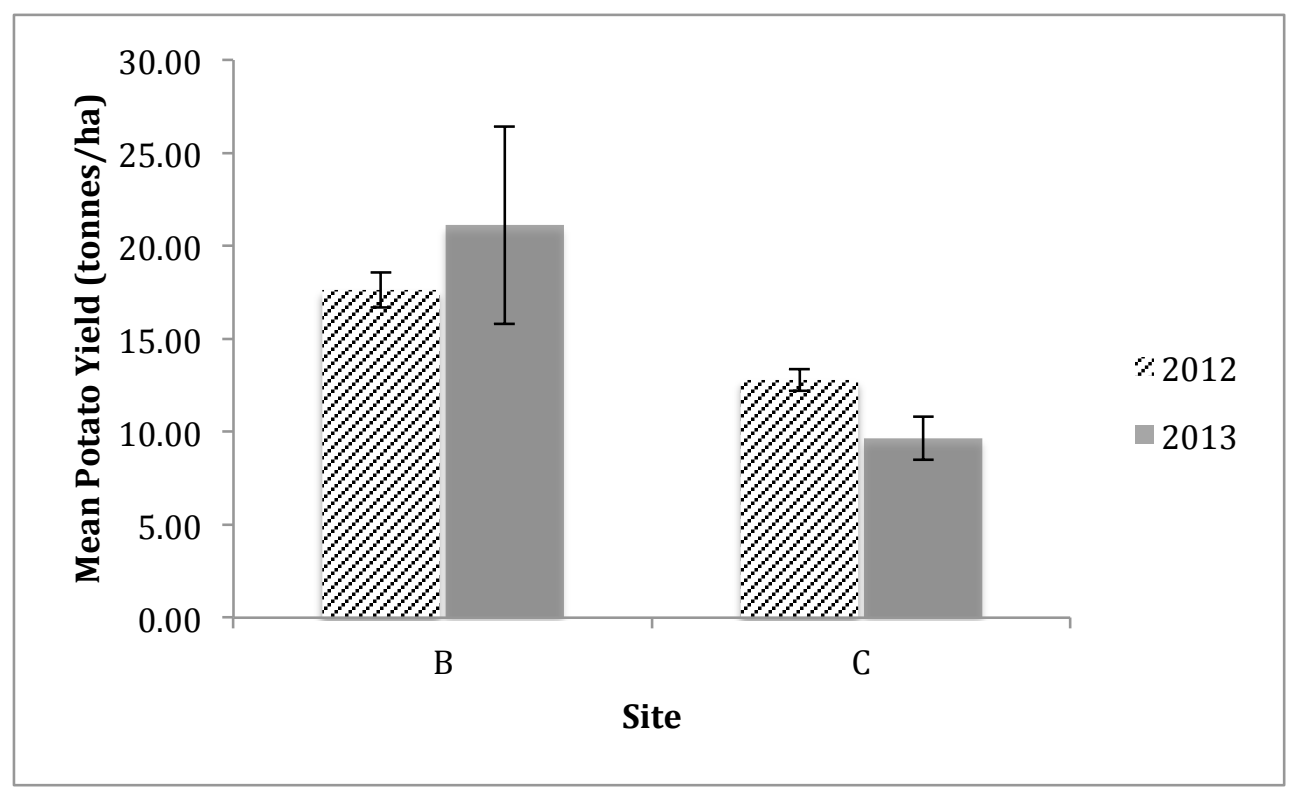

Figure 1. The yield of potatoes in tonnes/hectare produced in each site over the two field seasons. Error bars report standard error for the mean potato yield per plot.

When the mean potato yields for both sites from 2012 were compared to the most recent mean yield information available for provincial (Ontario), national (Canadian) and global potato production, it became apparent that potato production in the subarctic although less than the Canadian mean, was comparable to the global mean (Figure 2). If the mean yield for the treed site for the 2012 season is used in comparison to the provincial, national and global means, then not only is the yield greater than the global mean but it is close to the provincial and Canadian means.

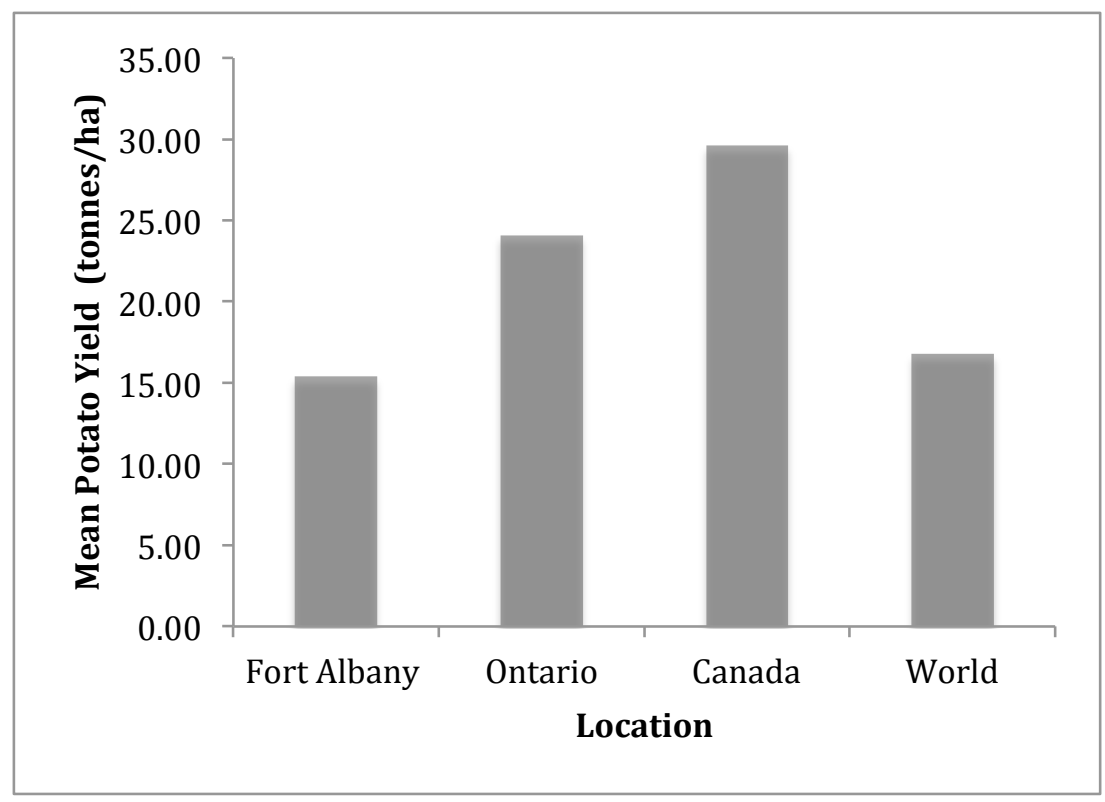

Figure 2. Comparing the potato yield from Fort Albany to reported provincial, national and global means of potato yields (tonnes/hectare) [38,39]. 


\subsection{Bean Harvest}

Although not the focus of this research, the bush beans were planted to support future potato production and improve potato sustainability, the beans proved to be an important crop that was given to the community. One community member stated that:

"Introducing the beans was really (an) eye opener for others that I gave to and for myself too. When I was collecting, when I took a bite of it, it was really sweet" (FA1)

Bush bean production appears to be successful in the two sites used during this study (Figure 3).

Similar to the potato yield, it was found that there was no significant interaction $(\mathrm{p}=0.76)$ between year and site, while the treed Site B produced significantly $(\mathrm{p}=0.01)$ more bush beans regardless of year. Furthermore, Beans picked throughout the study were given away to community members via a local store. Beans were placed in small bags and left in a basket for people to take home (Figure 4). Many people noted that they picked up the beans as they went through the checkout. Since bush beans were relatively new to many community members there was a pre-conceived belief that they had to be boiled before eating. However, after a team member explained that they could be eaten raw many people ate freshly picked beans without further processing.

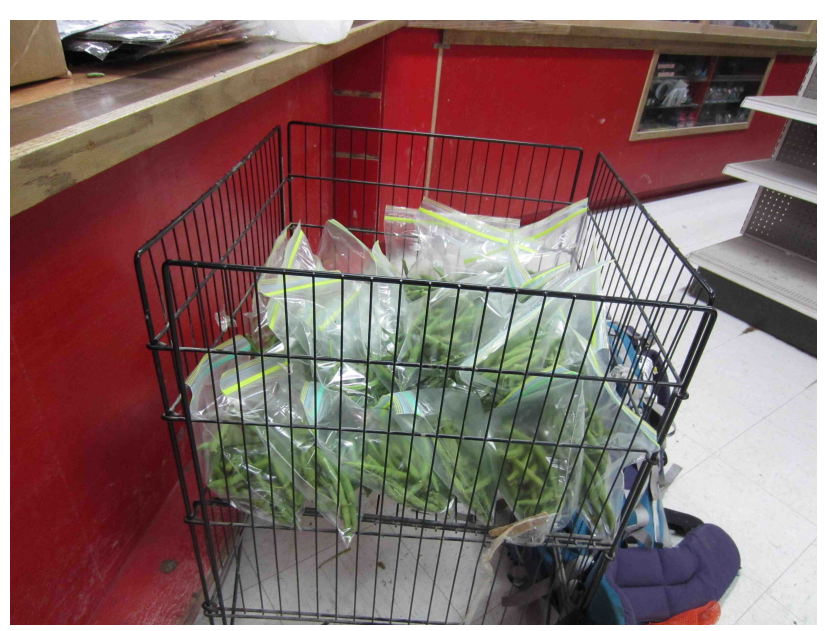

Figure 4. Basket of bush beans left at a local store for community members to bring home.

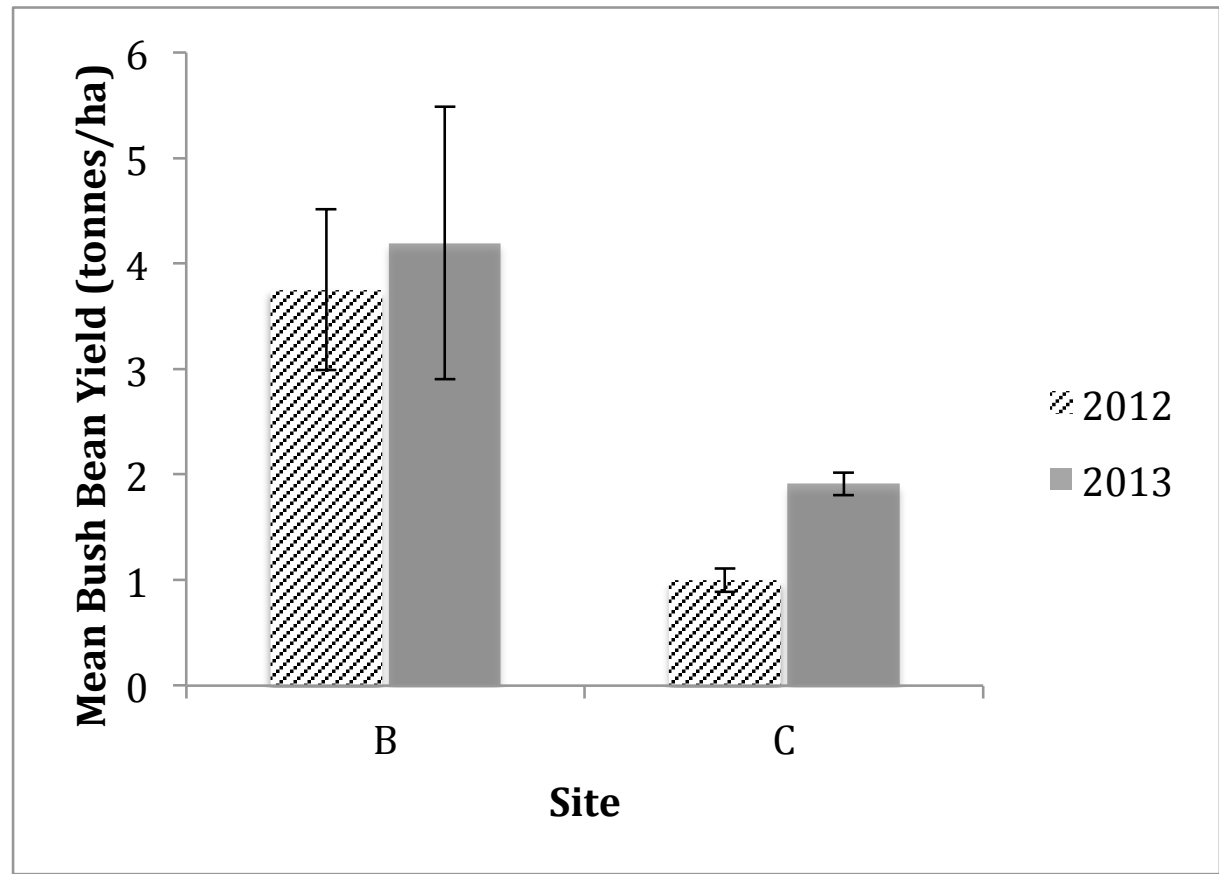

Figure 3. The mean yield of bush bean in tonnes/hectare produced in each site over the two field seasons. Error bars report standard error for the mean bush bean yield per plot. 


\subsection{Community Involvement and Food Security}

The community of Fort Albany was accepting and excited about the potential to grow potatoes in their community. One community member stated that:

"When we were harvesting the potatoes you hear a lot of interest, a lot of interest. They want to see it in their own backyard" (FA1)

When asked if people felt that this type of gardening would help the community their response was:

"I think this is a good idea, yeah for the community" (FA3)

"It helps me so I am sure it will help everybody" (FA2)

Community members noted many benefits of local potato production. One of the main benefits was that there was a sense of community ownership, it was "the community's thing" and that it brought people together to plant the crops and talk about gardening, and how they might start their own backyard potato patches. Some community members that attended the 2013 potato harvest already showed interest in planting potatoes on their property the following year. Furthermore, during the community harvest, it was noted how expensive the potatoes would have been if they had been purchased at the local store. One community member mentioned that a large majority of the produce available at the local store was imported and that they were concerned about potential contamination because they did not know under what environmental conditions the produce was grown. They felt that growing their own food in the community would help ensure that they would know what they were eating. Local potato production was seen by many people as a great opportunity to grow their own food and that it offered an opportunity to do things on their own and to look after themselves. When asked about the potential impacts of climate change and if warming temperatures might allow for more food production one community member stated that:

"When it comes to agriculture, you know planting, and it's really something that we should start getting into. And taking advantage of (the) warmer temperatures and trying to adapt with it. Because I mean if we are not going to adapt with it, I think that just at the end you are probably (going) to hurt yourself if we are not going to adapt to climate change" (FA1)

When asked if there was a future for local potato production in the community, many people thought there was. Numerous community members felt that many people "would pick it up" (FA3) and that the more people who saw the gardens and were involved, then the more likely it would be for the community to work together towards local food production. It was apparent that the key to the future of food production in the community is engagement including hands-on experience. 


\section{Discussion}

\subsection{Ecological Sustainability of Potato Production in Northern Aboriginal Communities}

Sustainable agricultural practices are developed over time. Sustainability is a process, and not merely a method or a set of rules or principles [40]. By thinking of sustainability as a process, we can set aside our pre-conceived notions of what is sustainable agriculture and move towards making informed decisions based on retrospective analysis of system-specific information. According to Rigby and Cáceres [40], in order to evaluate how sustainable a system is, we must ask ourselves this question: "given local conditions, and the agricultural and ecological history of an area, are the agricultural systems operating there becoming more sustainable, are they coming closer to achieving a goal that is constantly being refined and redefined as knowledge and attitudes change?" (p.33). The GAPs of sustainable potato production helped to guide our initial field trials. The goal was to understand if sustainable potato production was possible in northern First Nation communities. Based on yield information alone, potatoes can be successfully grown at levels close to the Canadian mean. This is an important finding because the yields reported for Ontario, Canada and the World (Figure 1) are from conventional high input potato production systems, while this study used a low-input process and received similar yields. This is a promising result indicating that local, low-input potato production can be successful and provide high yields to the community. Despite this success, there are common constraints related to long-term potato production that need to be addressed for continued sustainability (Table 2).

One of the greatest challenges with northern potato production is the accessibility and availability of seed potatoes. Seed potatoes for this study were shipped into the community from the closest supplier that was $404 \mathrm{~km}$ south of Fort Albany. Having to import seed by air is very expensive both financially and environmentally. Farmer seed systems (where farmers use potatoes stored from the previous season's crop as seed potato) offer the opportunity to address these challenges. Historically, there have been constraints surrounding farmer seed systems. This method can result in poor seed quality due to the increased chance of disease in seed potatoes due to improper storage and handling. However, formal training on proper care and storage of seed would help to overcome such challenges [33].

Recent research into sustainable potato production has developed no-till methods of production. During no-till methods potatoes are placed on the surface of the soil and then are covered by mulch, ideally straw. Potatoes then develop under the thick mulch and are easily harvested without digging. This method protects the soil from erosion, regulates soil temperature and moisture, builds soil organic matter and ensures the long-term availability of soil nutrients that help achieve high potato yields [33]. Future potato production in northern communities might be able to employ similar production methods using local plant material such as native legumes instead of straw.

The use of windbreaks also shows promise to increase potato yield while conserving the natural resource base. The treed site was located between rows of willow and produced greater yields compared to the open site for both crops and both seasons. Some of the main benefits of windbreaks include water and nutrient retention, wind protection, increased biodiversity, carbon sequestration, protection from soil erosion and microclimate regulation $[42,43]$. 
Table 2. Recommendations to Overcome Future Constraints to Sustainable Potato Production in Northern First Nation Communities

\begin{tabular}{|c|c|}
\hline Sustainability Constraints & Recommendations \\
\hline High Fertilizer Requirements & $\begin{array}{l}\text { - Addition of organic compost through } \\
\text { the development of community-wide } \\
\text { composting systems } \\
\text { - Use of community fish waste as } \\
\text { organic fertilizers } \\
\text { - Crop rotation with legumes [33] }\end{array}$ \\
\hline Lack of Efficient Seed Systems & $\begin{array}{l}\text { - } \begin{array}{l}\text { Training of community members to } \\
\text { harvest and store quality seed potatoes } \\
{[33]}\end{array} \\
\end{array}$ \\
\hline Prevalence of Diseases and Insect Pests & $\begin{array}{l}\text { - Use of three year crop rotation schedule } \\
\text { - Use of good quality seed and different } \\
\text { - } \text { Farieties } \\
\text { - } \quad \text { Use of integrated pest management } \\
\text { practices } \\
\text { - Community monitoring for the } \\
\text { beginning of disease and pest problems } \\
\text { [33] }\end{array}$ \\
\hline Conservation of Natural Resource Base & $\begin{array}{l}\text { Maintain soil organic matter by leaving } \\
\text { as much crop residue as possible } \\
\text { especially from beans or other native } \\
\text { legumes } \\
\text { - Minimum tillage (eg. autumn chisel } \\
\text { plow or spring disk) to maintain water- } \\
\text { use efficiency and nutrients [41] } \\
\text { - Use of windbreak/shelter belts to } \\
\text { improve soil quality and maintain soil } \\
\text { moisture } \\
\text { Use of mulch or cover-crop towards the } \\
\text { end of the growing season to help avoid } \\
\text { erosion over winter and to enhance } \\
\text { levels of soil organic matter [33] }\end{array}$ \\
\hline
\end{tabular}

\subsection{Social Sustainability of Potato Production in Northern Communities}

Local food production offers communities the opportunity to take control of their food, their health and their futures. Health and health promotion is a requirement of social sustainability but also requires community action through community development [44]. Community development focuses on using community resources, such as, local food production to empower communities to take control of their endeavors and future [44]. Recent research on the barriers driving food insecurity in Fort Albany identified empowerment as a key issue requiring attention [10]. Empowerment according to Wallerstein [45] is "a social action process that promotes participation of people, organizations, and 
communities towards the goals of increased individual and community control, political efficiency, improved quality of community life and social justice" (pp. 157). Spiegelaar et al. [34] found that community members felt disempowered due to their reliance on grocery stores and their lack of control over the quantity and quality of foods that were brought into their community. Local sustainable food production, whether from potatoes or other crops, has the potential to break the feeling of being tied to the grocery store and enhance social equity and democracy [34]. Community action and its resulting empowerment can enhance community resilience towards environmental change.

Community resilience has been reported as an important component of social sustainability [46]. Community resilience is defined as "the existence, development, and engagement of community resources by community members to thrive in an environment characterized by change, uncertainty, unpredictability, and surprise" [46:401]. In a region with documented environmental change, community resilience offers the opportunity for a community to respond to environmental change through adaptation [14]. Local food production has the potential to support mental wellbeing through individual and community empowerment. Recent research into local food production in Aboriginal communities found that producing local foods promoted feelings of health, wellness, life satisfaction and social capital $[47,48]$. The act of gardening has also promoted family time through the involvement of children in the food growing process [48]. Not only does this improve relationships between family members and among families, but it also has the potential to help support knowledge transfer between generations.

\subsection{The Future of Sustainable Food Production in Northern Communities}

When asked if there was a future for sustainable potato production in the community of Fort Albany, community members unanimously said there was. What is unknown is whether it would be in the form of larger plots of potato production as in this study and/or in the form of backyard home gardens, which we have also initiated [48]. Backyard home gardens would address the concern that the larger potato plots are not as centrally located and accessible to the community, as a backyard garden. Although not as visible and accessible, large community plots located away from the community have the benefits of avoiding vandalism and community dogs, which have been seen as a problem with backyard home gardens [48].

Financial constraints to local food production were noted as potential barriers to future crop production, especially in northern regions where seed and equipment, including rakes and shovels, must be imported. However, Vandenberg et al. found that despite financial requirements, many community members felt so positively towards local food production that they were willing to fund their own gardens [48]. Larger community plots could be supported through the work of volunteers, fundraisers, and the Band Office (i.e., locally elected government made of Chief and Band Council).

Knowledge and education on local food production was also viewed as a barrier to future success. Previous research into backyard gardens reported that many community members reported feeling they lacked important skills such as trouble identifying vegetables (due to a lack of familiarity) and weeds, and understanding proper planting and harvesting techniques [48]. One example observed during this study was the lack of familiarity with bush beans. Hands-on workshops on sustainable growing practices and vegetable use have recently been given by our research group to help provide 
information, and empower community members with the knowledge required to successfully grow their own food whether in their backyards or in community plots. Indeed, our research team has even held youth camps where a large component of hands-on activities included visits to the community plots, to begin engaging the next generation [49].

\section{Conclusions}

A warming climate in the arctic and subarctic offers opportunities for northern Canadian Aboriginal communities - and other subarctic and potentially arctic communities world-wide - to sustainably grow local foods to promote food security. Through the use of more sustainable agricultural practices, potatoes were successfully produced alongside bush beans in subarctic Ontario, Canada. Community members acknowledged the benefits of local food production and believed that there was a future for more sustainable food production in their community. Introducing local food production systems in northern Aboriginal communities worldwide may foster empowerment and enhance community resilience toward future challenges.

\section{Acknowledgments}

We would like to thank Fort Albany First Nation for their involvement in this research and the Institute of Aboriginal Peoples' Health (Canadian Institutes of Health Research) for funding support.

\section{Conflicts of Interest}

The authors declare no conflict of interest.

\section{References and Notes}

1. Statistics Canada. Projections of the Aboriginal Populations, Canada, Provinces and Territories, 2001 to 2017 (catalogue number 91-547-XIE). 2001.

2. Macdonald, M.E.; Rigillo, N.; Brassard, P. Urban aboriginal understandings and experiences of tuberculosis in Montreal, Quebec, Canada. Quality Health Research 2010, 20(4), 506-523.

3. MacMillan, H.; MacMillan, A.; Offord, D.; Dingle, J. Aboriginal Health. Canadian Medical Association Journal 1996, 155(11), 1569-1578.

4. Ford, J.D.; Pearce, T.; Duerden, F.; Furgal, C.; Smit, B. Climate change policy responses for Canada's Inuit population: The importance of and opportunities for adaptation. Global Environmental Change 2010, 20, 177-191.

5. Gates, A.; Hanning, R.M.; Gates, M.; Skinner, K.; Martin, I.D.; Tsuji, L.J.S. Vegetable and Fruit Intakes of On-Reserve First Nations Schoolchildren Compared to Canadian Averages and Current Recommendations. International Journal of Environmental Research and Public Health 2012, 9. 1379-1397. 
6. Anand, S.S.; Yusuf, S.; Jacobs, R.; Davis, A.D.; Yi, Q. et al. Risk factors, atherosclerosis, and cardiovascular disease among Aboriginal people in Canada: the Study of Health Assessment and Risk Evaluation in Aboriginal Peoples. Lancet 2001, 358, 1147-1153.

7. Skinner, K; Hanning, R; Tsuji, L. Barriers and supports for healthy eating and physical activity for First Nation youths in Northern Canada. International Journal of Circumpolar Health 2006, $65(2), 148-161$.

8. Shields, M. Nutrition: Findings from the Canadian Community Health Survey - overweight Canadian children and adolescents. Statistics Canada 2005, 82-620-MWE, 2-34.

9. Gates, A; Hanning R.M.; Gates, M.; Isogai, A.D.; Metatawabin, J.; Tsuji, L.J.S. A school nutrition program improves vegetable and fruit knowledge, preferences, and exposure in First Nation youth. The Open Nutrition Journal 2011, 5,22-27.

10. Skinner, K. Prevalence and Perceptions of Food Insecurity and Coping Strategies in Fort Albany First Nation, Ontario. PhD Thesis. University of Waterloo, Waterloo, Ontario. Canada. 2013.

11. Fox, C.; Harris, S.B.; Whalen-Brough, E. Diabetes among Native Canadians in northwestern Ontario: 10 years later. Chron Dis Can 1994,15:92-96.

12. Sistili, B.; Metatawabin, M.; Iannucci, G.; Tsuji, L.J.S. An Aboriginal Perspective on the Remediation of Mid-Canada Radar Line Sites in the Subarctic: A Partnership Evaluation. Arctic 2006, 59(2),142-154.

13. Spiegelaar, N.F.; Tsuji, L.J.S. Impact of Euro-Canadian agrarian practices: in search of sustainable import-substitution strategies to enhance food security in subarctic Ontario, Canada. Rural and Remote Health 2013, 6:2211, 1-17.

14. Barbeau, C.D.; Hori, Y.; Gough, W.A.; Karagatzides, J.D.; McCarthy, D.; Cowan, D.; Tsuji, L.J.S. The Potential Use of an Interactive Web-Based Informatics Tool to Decrease the Incidence of Human-Polar Bear Encounters Along the Western James Bay Coast of Ontario, Canada. The International Journal of Technology, Knowledge and Society 2013, 8(5):113-127.

15. Willows, N. Determinants of Healthy Eating in Aboriginal Peoples in Canada: The Current State of Knowledge and Research Gaps. Canadian Journal of Public Heath 2005, 96(3), S32S36.

16. Indian and Northern Affairs Canada (INAC). Nutrition and Food Security in Fort Severn, Ontario. 2004. Available Online: http://dsp-psd.pwgsc.gc.ca/Collection/R2-350-2004E.pdf (accessed on 05/12/2010).

17. Indian and Northern Affairs Canada (INAC). Revised Northern Food Basket-Highlights of Price Survey Results for 2006 and 2007. 2009. Available Online: http://www.aincinac.gc.ca/nth/fon/fm/ar/hpsr0607-eng.asp (accessed on 11/1/2013)

18. Papatsie, L. Which Cultures Benefit from the Nutrition North Program? Nunatsiaq News. Available Online:http://www.nunatsiaqonline.ca/stories/article/9876789_which_culture_benefits_from_n utrition_north_program/ (accessed on 09/09/2014) 
19. Skinner, K; Hanning, R.M; Tsuji, L.J.S. Prevalence and severity of household food insecurity of First Nations people living in an on-reserve, sub-arctic community within the Mushkegowuk Territory. Public Health Nutrition 2013, 17(1) 31-39.

20. Hodge, I. Sustainability: putting principles into practice. An application to agricultural systems. Proceedings of the Rural Economy and Society Study Group, Royal Holloway College, United Kingdom, December 1993.

21. Hengeveld, H.; Whitewood, B.; Fergusson, A.; Environment Canada. An introduction to climate change: a Canadian perspective. Environment Canada 2005. Minister of Public Works and Government Services. pp 1-69.

22. IPCC. Climate Change 2007: Synthesis Report. Contribution of Working Groups I, II and III to the Fourth Assessment Report of the Intergovernmental Panel on Climate Change [Core Writing Team, Pachauri, R.K.; Reisinger, A, Eds]. 2007. IPCC, Geneva, Switzerland, 104 pp.

23. Ford, J.D.; Smit. B. A Framework for Assessing the Vulnerability of Communities in the Canadian Arctic to Risks Associated with Climate Change. Arctic 2004, 57(4),389-400.

24. Christensen, J.H.; Hewitson, B.; Busuioc, A.; Chen, A.; Gao, X. et al. Regional Climate Projections. In: Climate Change 2007: The Physical Science Basis. Contribution of Working Group I to the Fourth Assessment Report of the Intergovernmental Panel on Climate Change [Solomon, S., D. Qin, M. Manning, Z. Chen, M. Marquis, K.B. Averyt, M. Tignor and H.L. Miller (eds.)]. 2007. Cambridge University Press, Cambridge, United Kingdom and New York, NY, USA.

25. Riley, J.L. Wetlands of the Ontario Hudson Bay Lowland: A Regional Overview. Nature Conservancy of Canada, Toronto, ON. 2011. 156 pp., app.

26. Hori, Y. The Use of Traditional Environmental Knowledge to Assess the Impact of Climate Change on Subsistence Fishing in the James Bay Region, Ontario, Canada. Masters Thesis. University of Waterloo, Waterloo, Ontario. Canada. 2010.

27. Gough, W.A.; Gagnon, A.S.; Lau, H.P. Interannual Variability of Hudson Bay Ice Thickness. Polar Geography 2004, 28(3), 222-238.

28. Stirling, I.; Parkinson, C. Possible effects of climate warming on selected populations of polar bears (Ursus maritimus) in the Canadian Arctic. Arctic 2006, 59, 261-275.

29. Wenstob, S. The Profusion of Potatoes in Pre-Colonial British Columbia. Platforum 2011, 12, 133-160.

30. International Arctic Science Committee. Agriculture in the Arctic. Section 14.5 of the Arctic Climate Impact Assessment. 2012. Available Online:

http://www.eoearth.org/view/article/149915 (accessed on 07/10/2014).

31. Kolasa, K.M. The Potato and Human Nutrition. American Potato Journal 1993, 70, 375-384. 
32. Potato Research Centre. A Century of Science. Agriculture and Agri-food Canada. 2012. Available Online: http://www.agr.gc.ca/eng/science-and-innovation/research-centres/atlanticprovinces/potato-research-centre/a-century-of-science/?id=1345559675096 (accessed on 05/03/2012).

33. Lutaladio, N.; Ortiz, O.; Haverkort, A.; Caldiz, D. Sustainable Potato Production: Guidelines for Developing Countries. Food and Agricultural Organization of the United Nations. 2009. Available Online: http://www.fao.org/docrep/012/i1127e/i1127e00.htm

34. Spiegelaar, N. Agroforestry Community Gardens as a Sustainable Import-Substitution Strategy for Enhancing Food Security in Remote First Nations of Subarctic Ontario, Canada. Master's Thesis. University of Waterloo. Waterloo, Ontario, Canada. 2011.

35. Crabtree BF, Miller WL. Using codes and code manuals: a template organizing style of interpretation. In Doing qualitative research, $2^{\text {nd }}$ ed. Crabtree, B.F.; Miller, W.L, Eds. Newbury Park, CA: Sage Publications, 1999; pp.163-177.

36. Bryman A. Social Research Methods. New York, NY: Oxford University Press, 2001.

37. Glass, G.V.; Peckham, P.D.; Sanders, J.R. Consequences of Failure to Meet Assumptions Underlying the Fixed Effects Analyses of Variance and Covariance. Review of Educational Research 1972, 42(3) pp 237-288.

38. Statistics Canada. Canadian Potato Production: Table 6 - Area, production and value of all potatoes, Canada (metric measure). 2013. Available Online: http://www.statcan.gc.ca/pub/22008-x/2012002/t016-eng.htm (accessed on 08/11/2014).

39. FAO. International Year of the Potato. Potato World. 2008. Available Online: http://www.fao.org/potato-2008/en/world/index.html (accessed on 08/11/2014).

40. Rigby, D.; Cáceres, D. Organic farming and the sustainability of agricultural systems. Agricultural Systems 2001, 68, 21-40.

41. Sharratt, B.; Zhang, M.; Sparrow, S. Twenty years of conservation tillage research in subarctic Alaska II. Impact on soil hydraulic properties. Soil and Tillage Research 2006, 91, 82-88.

42. Schroth, G.; Sinclair, F.L. Impacts of Trees on the Fertility of Agricultural Soils. In: Tree, Crops and Soil Fertility. Schroth, G.; Sinclair, F.L, Eds. 2003. CABI Publishing, Oxon. UK. pp $1-11$.

43. Izac, A. Economic Aspects of Soil Fertility Management and Agroforestry Practices. In Tree, Crops and Soil Fertility. Schroth, G.; Sinclair, F.L, Eds. 2003. CABI Publishing, Oxon. UK. pp 13-37.

44. WHO. Ottawa Charter for Health Promotion 1986. Available Online: http://www.who.int/healthpromotion/conferences/previous/ottawa/en/. (accessed on 09/09/2014).

45. Wallerstein, N. Powerlessness, Empowerment and Health: Implications for Health Promotion Programs. American Journal of Health Promotion 1992, 6(2), 197-205. 
46. Magis, K. Community Resilience: An Indicator of Social Sustainability. Society \& Natural Resources: An International Journal 2010, 23(5), 401-416.

47. Stroink, M. L.; Nelson, C. H. Aboriginal health learning in the forest and cultivated gardens: building a nutritious and sustainable food system. Journal of Agromedicine 2009, 14(2), 263269.

48. Vandenburg, S.C. Improving Access to Fresh Vegetables: Home Gardening in Remote First Nation Communities. Masters Thesis. University of Waterloo, Waterloo, Ontario. Canada. 2014.

49. Isogai, A.D.; Alexiuk, E.; Gardner, H.L.; McCarthy, D.D.; Edwards, V.; Spiegelaar, N.; Tsuji L.J.S. Sustaining a local-food security initiative in a remote subarctic community: Engaging Canadian First Nation youth in agroforestry-community gardens. International Journal of Social Sustainability in Economic, Social and Cultural Context 2014, 9. 